\title{
Tailoring Confining Jacket for Concrete Column Using Ultra High Performance-Fiber Reinforced Cementitious Composites (UHP-FRCC) with High Volume Fly Ash (HVFA)
}

\author{
Alessandro P. Fantilli ${ }^{1, *}$, Lucia Paternesi Meloni ${ }^{1,2}$, Tomoya Nishiwaki ${ }^{2}$ and Go Igarashi ${ }^{2,3}$ \\ 1 Department of Structural, Geotechnical and Building Engineering, Politecnico di Torino, 10129 Torino, Italy; \\ s238354@studenti.polito.it \\ 2 Department of Architecture and Building Science, Tohoku University, Sendai 980-8579, Japan; \\ tomoya.nishiwaki.e8@tohoku.ac.jp (T.N.); go.igarashi@concrete.t.u-tokyo.ac.jp (G.I.) \\ 3 Department of Civil Engineering, The University of Tokyo, Tokyo 113-8656, Japan \\ * Correspondence: alessandro.fantilli@polito.it; Tel.: +39-011-090-4900
}

Received: 4 October 2019; Accepted: 26 November 2019; Published: 3 December 2019

\begin{abstract}
Ultra-High Performance Fibre-Reinforced Cementitious Composites (UHP-FRCC) show excellent mechanical performances in terms of strength, ductility, and durability. Therefore, these cementitious materials have been successfully used for repairing, strengthening, and seismic retrofitting of old structures. However, UHP-FRCCs are not always environmental friendly products, especially in terms of the initial cost, due to the large quantity of cement that is contained in the mixture. Different rates of fly ash substitute herein part of the cement, and the new UHP-FRCCs are used to retrofit concrete columns to overcome this problem. To simulate the mechanical response of these columns, cylindrical specimens, which are made of normal concrete and reinforced with different UHP-FRCC jackets, are tested in uniaxial compression. Relationships between the size of the jacket, the percentage of cement replaced by fly ash, and the strength of the columns are measured and analyzed by means of the eco-mechanical approach. As a result, a replacement of approximately $50 \%$ of cement with fly ash, and a suitable thickness of the UHP-FRCC jacket, might ensure the lowest environmental impact without compromising the mechanical performances.
\end{abstract}

Keywords: high volume fly ash (HVFA); steel reinforcing fiber; jacketing; carbon footprint; substitution strategy; environmental impact

\section{Introduction}

In the last decades, Ultra-High Performance Fiber-Reinforced Cementitious Composites (UHP-FRCC) have been developed to meet the requests of the construction industry [1-3]. UHP-FRCCs can enhance the resistance of buildings and infrastructures due to the ultra-high strength, high ductility, durability, and energy absorption capacity, when compared with normal strength concrete or traditional FRCC. In fact, UHP-FRCCs show a compressive strength that was larger than $150 \mathrm{MPa}$, combined with high tensile and flexural strengths. Such performances are achieved with a low water/binder ratio, high content of cementitious materials, and by incorporating a copious amount of fibers (steel, polymeric, glass, etc.) [4-7].

One of the most well-known and relevant applications of UHP-FRCC is the retrofitting of existing structures, especially the jacketing of concrete columns and beams, due to these mechanical properties. The aim is to harden those parts of the existing structures that are exposed to high environmental 
and mechanical actions, especially in the most highly stressed cross-sections and in the structural joints [8-10].

However, this high-performance material has, in parallel, high environmental impact, because of the high content of cement in the mixture $[3,5,6,11,12]$. Indeed, it is unanimously accepted that the compressive strength of concrete is in direct proportion with the power 2 of the cement content and, consequently, this strength is proportional to the power 2 of the $\mathrm{CO}_{2}$ emission per cubic meter of concrete. Therefore, the "material substitution strategy" that Habert and Roussel introduced [11] is generally adopted. As the name suggests, it consists of a partial replacement of cement with supplementary cementitious materials, in order to reduce the environmental impact. Specifically, different amounts of cement are substituted by fly ash, a waste by-product that is derived from coal burning. When the mass of fly ash is higher than $50 \%$ of the total cementitious materials, the concrete system takes the name of High Volume Fly Ash (HVFA) [13]. It must be remarked that the substitution of cement with fly ash might not always be beneficial. HVFA significantly reduces the environmental impact, but it also leads to a decrease of concrete strength, especially in the UHP-FRCC [14,15].

Some researches, regarding the high strength concrete and UHP-FRC using high quantity of admixtures from by-products, were performed in the last years [16-18]. On the other hand, most of these studies only focused on the development of the cement-based material, without focusing on the structural applications. Accordingly, a new experimental campaign has been carried out on normal-strength concrete cylinders that were reinforced with UHP-FRCC jackets, with the aim of simulating the confinement effect in columns. Different jackets are tailored to investigate the relationship between the thickness of the reinforcing layer and the mechanical performances of the reinforced column. In some of them, different percentages of fly ash substitute the cement for achieving the best mechanical and ecological performances [19]. A design procedure is also proposed to select the best solution by defining the optimal replacement rate of cement with fly ash.

\section{Experimental Investigation: Materials and Methods}

Figure 1 illustrates the cylindrical sample subjected to uniaxial compression. It consists of a normal-strength concrete core, with a radius $r_{0}=50 \mathrm{~mm}$ and a height $H=200 \mathrm{~mm}$, confined by a UHP-FRCC jacket of $H_{1}=178 \mathrm{~mm}$ and different thickness $\left(t_{\mathrm{i}}=25,37.5,50\right.$, and $\left.75 \mathrm{~mm}\right)$. As no standard exists to test the confinement effects, the minimum thickness of $25 \mathrm{~mm}$ was determined due to the limitation of the casting procedures of the UHP-FRCC layer into a narrow gap.

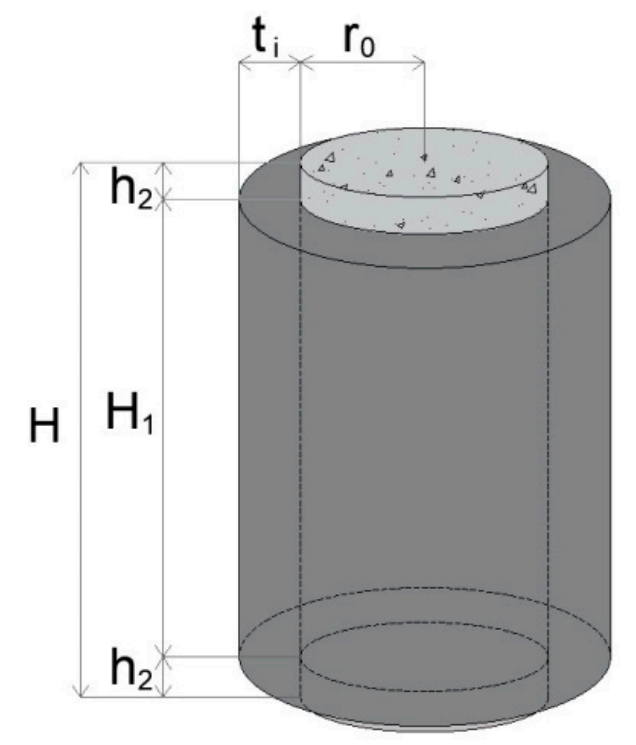

Figure 1. Geometrical properties of the specimens. 
According to the mix proportion that is shown in Table 1, the concrete cores have been made with High Early Strength Portland Cement (HESP; Density: $3.14 \mathrm{~g} / \mathrm{cm}^{3}$, Specific surface area: $4490 \mathrm{~cm}^{2} / \mathrm{g}$ Ignition loss: $1.08 \%$ ), the combination of land sand and crushed sand as fine aggregates (S), crushed stone as coarse aggregates $(\mathrm{G})$, tap water $(\mathrm{W})$, and superplasticizer $\left(\mathrm{SP}_{1}\right.$; Polycarboxylate-based, Density: $1.03 \mathrm{~g} / \mathrm{cm}^{3}$ ).

Table 1. Concrete mixture used to cast the cores.

\begin{tabular}{ccccc}
\hline $\begin{array}{c}\text { HESP } \\
\left(\mathbf{k g} / \mathbf{m}^{3}\right)\end{array}$ & $\begin{array}{c}\mathrm{S} \\
\left(\mathbf{k g} / \mathbf{m}^{3}\right)\end{array}$ & $\begin{array}{c}\mathrm{G} \\
\left(\mathbf{k g} / \mathbf{m}^{3}\right)\end{array}$ & $\begin{array}{c}\mathrm{W} \\
\left(\mathbf{k g} / \mathbf{m}^{3}\right)\end{array}$ & $\begin{array}{c}\mathrm{SP}_{\mathbf{1}} \\
\left(\mathbf{k g} / \mathbf{m}^{3}\right)\end{array}$ \\
\hline 300.3 & 836 & 900.3 & 171.7 & 1.7 \\
\hline
\end{tabular}

The UHP-FRCCs used herein are made by the following materials $[3,13,14]$ :

- Low Heat Portland Cement (LHC; Density: $3.24 \mathrm{~g} / \mathrm{cm}^{3}$, Specific surface area: $3640 \mathrm{~cm}^{2} / \mathrm{g}, \mathrm{C}_{2} \mathrm{~S}$ : $57 \%, \mathrm{C}_{3} \mathrm{~A}: 3 \%$, MgO: $0.6 \%, \mathrm{SO}_{3}: 2.78 \%$, Ignition loss: $0.72 \%$ )

- Undensified Silica Fume (SF; Density: $2.20 \mathrm{~g} / \mathrm{cm}^{3}$, Bulk density: $0.20-0.35 \mathrm{~g} / \mathrm{cm}^{3}$, Coarse particles $>45 \mu \mathrm{m}$ : less than $1.5, \mathrm{SiO}_{2}$ : more than $90 \%$, Ignition loss: less than $3.0 \%$ )

- Fly Ash (FA; Density: $2.31 \mathrm{~g} / \mathrm{cm}^{3}$, Specific surface area: $4050 \mathrm{~cm}^{2} / \mathrm{g}$, Coarse particles $>45 \mu \mathrm{m}: 5 \%$, $\mathrm{SiO}_{2}: 54.8 \%$, Ignition loss: $1.2 \%$ )

- Silica sand (Ss; Density: $2.60 \mathrm{~g} / \mathrm{cm}^{3}$, Average particle size: $0.212 \mathrm{~mm}, \mathrm{SiO}_{2}: 98.49 \%, \mathrm{Al}_{2} \mathrm{O}_{3}: 0.49 \%$ )

- Wollastonite mineral fibers (Wo; $\mathrm{CaSiO}_{3}$, Density: $2.60 \mathrm{~g} / \mathrm{cm}^{3}$, Length: 50-2000 $\mu \mathrm{m}$, Aspect ratio: 3-20, $\mathrm{SiO}_{2}: 49.71 \%$, $\mathrm{CaO}: 45.87 \%$, Ignition loss: $1.94 \%$ )

- Specific superplasticizer ( $\mathrm{SP}_{2}$; Polycarboxylate-based, Density: $1.05 \mathrm{~g} / \mathrm{cm}^{3}$, Solid part: $30 \%$ )

- De-foaming Agent (DA; Density: $1.05 \mathrm{~g} / \mathrm{cm}^{3}$ )

- Steel micro-fibers (OL-1\% in volume), with a length of $6 \mathrm{~mm}$ (see Figure 2a)

- $\quad$ Steel macro-fibers (HDR-1.5\% in volume), with a length of $30 \mathrm{~mm}$ (see Figure $2 \mathrm{~b}$ )

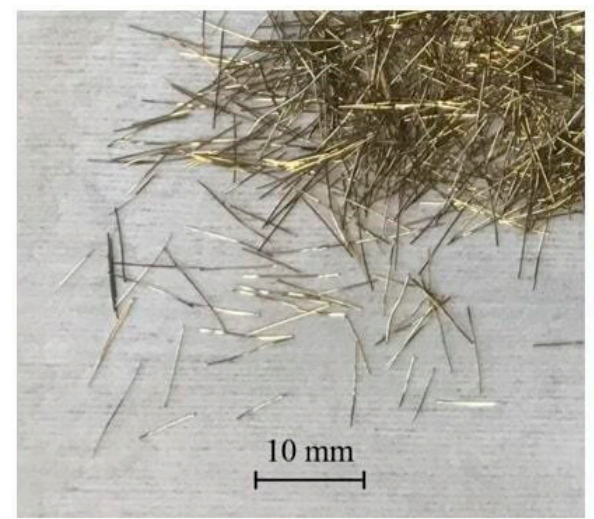

(a)

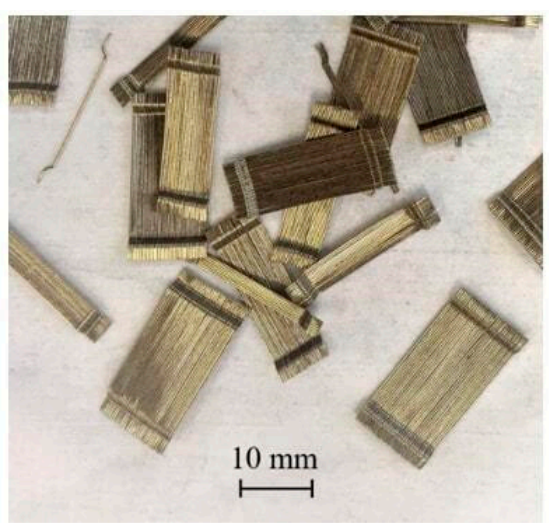

(b)

Figure 2. Steel Micro-fibers OL (a) and steel Macro-Fibers HDR (b) used to reinforce the Ultra-High Performance Fibre-Reinforced Cementitious Composites (UHP-FRCC) layers.

Following the material substitution strategy, four mixtures have been tailored for the UHP-FRCC jackets, modifying only the percentage of cement and fly ash. Table 2 shows the mix proportion of the four series of UHP-FRCC (FA0, FA20, FA50, and FA70), with, respectively, $0 \%, 20 \%, 50 \%$, and $70 \%$ of cement replaced by fly ash. In this Table, the components of each series are reported as a percentage with respect to the weight of the binder, whereas Table 3 shows the mix proportion of UHP-FRCC jackets in $\mathrm{kg} / \mathrm{m}^{3}$. In each series, the water-binder ratio is constant and equal to 0.16 , because it guarantees a good balance between the flowability properties and the strength of the hardened 
concrete, according to the authors' previous study [3]. Note that $\mathrm{SP}_{2}$ contains $30 \%$ of the solid part, which is taken into account to calculate the water-binder ratio. The flow table tests were performed in accordance with the Japanese Standard JIS R 5201 [20], which complies with ASTM C 1437 [21]. In particular, for FA0, FA20, FA50, and FA70, a diameter of $190 \mathrm{~mm}, 260 \mathrm{~mm}, 290 \mathrm{~mm}$, and $250 \mathrm{~mm}$, was, respectively, measured in the tests. Having these consistencies, all of the UHP-FRCs were cast and compacted in the jacket mould without any segregation.

Ten days after casting the concrete cores (which simulate herein an existing column), the UHP-FRCC jackets are cast around using paper cylinders with a height of $178 \mathrm{~mm}$ as a disposable formwork, as the proposed jacket has to be applied to existing structures.

Table 2. Mix proportion of the UHP-FRCC (in weight \%) referred to the binder (B).

\begin{tabular}{ccccccccc}
\hline \multirow{2}{*}{ Series } & \multicolumn{3}{c}{ Binder (B) } & \multirow{2}{*}{ Ss/B } & Wo/B & W/B & SP $/$ / & DA/B \\
\cline { 2 - 4 } & LH C/B & FA/B & SF/B & & & & & \\
\hline FA0 & 82 & & 18 & 35 & 13 & 14.5 & 2.2 & 0.02 \\
FA20 & 65.6 & 16.4 & 18 & 35 & 13 & 14.3 & 2.6 & 0.02 \\
FA50 & 41 & 41 & 18 & 35 & 13 & 14.3 & 2.6 & 0.02 \\
FA70 & 24.6 & 57.4 & 18 & 35 & 13 & 14.3 & 2.6 & 0.02 \\
\hline
\end{tabular}

Table 3. Mix proportion of UHP-FRCC jackets in $\mathrm{kg} / \mathrm{m}^{3}$.

\begin{tabular}{ccccccccc}
\hline Series & $\begin{array}{c}\mathbf{L H C} \\
\left(\mathbf{k g} / \mathbf{m}^{\mathbf{3}}\right)\end{array}$ & $\begin{array}{c}\text { FA } \\
\left(\mathbf{k g} / \mathbf{m}^{\mathbf{3}}\right)\end{array}$ & $\begin{array}{c}\text { SF } \\
\left(\mathbf{k g} / \mathbf{m}^{\mathbf{3}}\right)\end{array}$ & $\begin{array}{c}\text { Ss } \\
\left(\mathbf{k g} / \mathbf{m}^{\mathbf{3}}\right)\end{array}$ & $\begin{array}{c}\text { Wo } \\
\left(\mathbf{k g} / \mathbf{m}^{\mathbf{3}}\right)\end{array}$ & $\begin{array}{c}\mathbf{W} \\
\left(\mathbf{k g} / \mathbf{m}^{\mathbf{3}}\right)\end{array}$ & $\begin{array}{c}\mathbf{S P}_{\mathbf{2}} \\
\left(\mathbf{k g} / \mathbf{m}^{\mathbf{3}}\right)\end{array}$ & $\begin{array}{c}\text { DA } \\
\left(\mathbf{k g} / \mathbf{m}^{\mathbf{3}}\right)\end{array}$ \\
\hline FA0 & 1217.52 & & 267.26 & 519.67 & 193.02 & 214.70 & 32.67 & 0.30 \\
FA20 & 939.24 & 234.81 & 257.72 & 501.12 & 186.13 & 204.74 & 37.23 & 0.29 \\
FA50 & 558.33 & 558.33 & 245.12 & 476.63 & 177.03 & 194.74 & 35.41 & 0.27 \\
FA70 & 324.43 & 757.00 & 237.39 & 461.59 & 171.45 & 188.59 & 34.29 & 0.26 \\
\hline
\end{tabular}

Subsequently, the paper formworks were removed two days later and the specimens were subjected to steam curing for the following $48 \mathrm{~h}$. In this way, the hydration process of the binder was accelerated, especially in the UHP-FRCC jackets containing large amounts of fly ash. As depicted in Figure 3, the temperature was slowly increased at a rate of $15^{\circ} \mathrm{C}$ per hour up to $90^{\circ} \mathrm{C}$ to avoid any crack generation produced by the thermal gradient. Uniaxial compression tests are performed after 28 days from the concrete core casting. A universal testing machine (UTM) with a maximum capacity of $1000 \mathrm{kN}$ is used to apply the compressive load by moving the displacement of the stroke (of the loading cell) at a constant velocity of less than $0.3 \mathrm{~mm} / \mathrm{min}$. external strain gauges and embedded strain gauges were used to measure the strain during the tests.

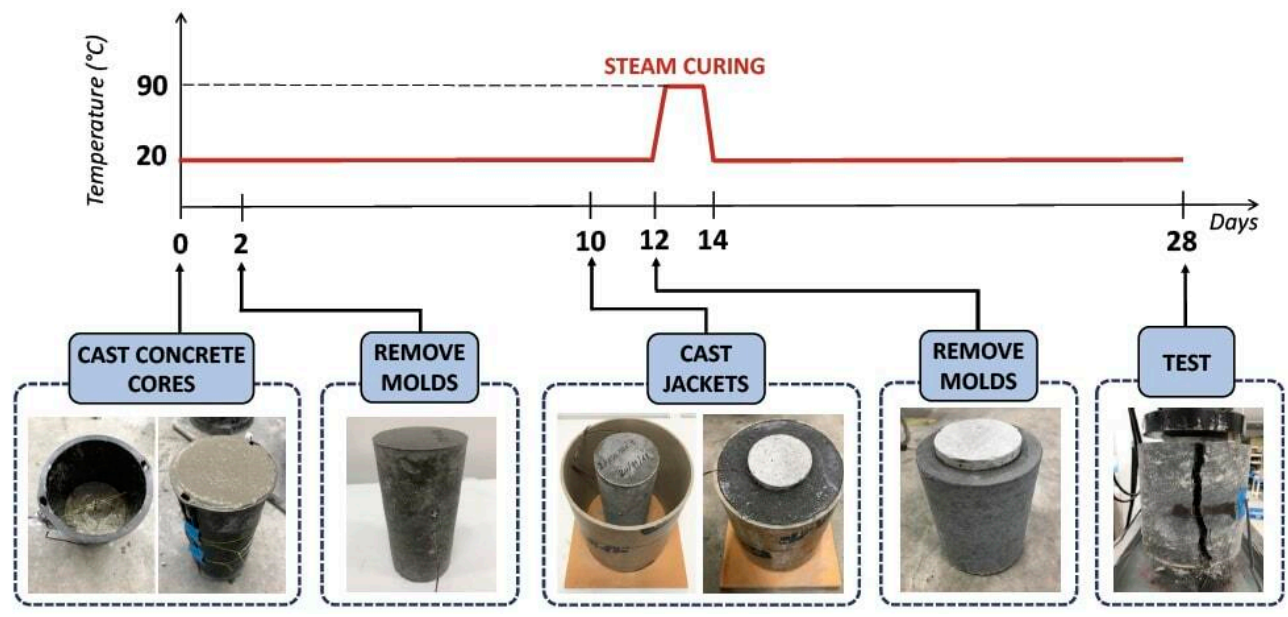

Figure 3. The preparation of the specimens. 
Four strain gauges are applied on the jacket's surface: two in the vertical direction and two in the horizontal direction. The vertical gauges measure the strain along the longitudinal axis, while those horizontally oriented gauges measure the swelling of the specimen. Embedded strain gauges were installed inside in the middle of the moulds before casting the concrete cores to record the vertical strain of the concrete core during the compression test.

As shown in Table 4, for some of the thickness of the jacket, three samples are tested for each mixture. In addition, for each series, one concrete core with no reinforcement is tested to estimate the mechanical properties without UHP-FRCC jackets.

Table 4. List of specimens tested in uniaxial compression.

\begin{tabular}{|c|c|c|c|c|}
\hline \multirow{2}{*}{ Series } & \multicolumn{4}{|c|}{ Thickness of the UHP-FRCC Jacket } \\
\hline & $25(\mathrm{~mm})$ & $37.5(\mathrm{~mm})$ & $50(\mathrm{~mm})$ & $75(\mathrm{~mm})$ \\
\hline FA0 & 3 specimens & & 3 specimens & \\
\hline FA20 & 3 specimens & 3 specimens & 3 specimens & 3 specimens \\
\hline FA50 & 3 specimens & & 3 specimens & \\
\hline FA70 & 3 specimens & 3 specimens & 3 specimens & \\
\hline
\end{tabular}

\section{Results}

\subsection{Mechanical Performances}

Table 5 shows the mechanical properties of the UHP-FRCC used in the jackets. The compressive strength and the elastic modulus both do not change with age because of the acceleration of hydration due to the steam curing. Table 5 summarizes the results of the uniaxial compression tests on the jacketed specimens. In this table, the average values of the maximum load $\left(\mathrm{P}_{\max }\right)$-and of the compressive strength $\left(\sigma_{\max }\right)$ as well, the Young Modulus $\left(E_{\mathrm{cm}}\right)$ and the Poisson's Ratio $(v)$ of the composite specimens are reported. $E_{\mathrm{cm}}$ and $v$ were both calculated at one-third of the maximum load, according to the Japanese Standard JIS A 1149 [22], which complies with ISO 6784 [23]. In Table 6, the strength is also normalized with respect to the strength of the unconfined concrete cylinders (i.e., $\left.\mathrm{f}_{\mathrm{c}_{-} \text {CORE }}\right) . E_{\mathrm{cm}}$ increased with the thickness of the jacket due to the confined effect. In the same manner, $v$ decreased as the jacket thickness increased. The tests on the specimen that is shown in Figure 1 were performed until the failure, which is generally produced by the formation of a large tensile crack in the UHP-FRCC jacket (see the right edge photo of Figure 3). During the first stage of loading, the jacked was uncracked and a linear relationship between the stress (calculated by dividing the load by the cross-sectional area of the core concrete) and the strain can be observed (see Figure 4). When the first crack appeared in the jacket, the slope of this relationship drastically reduces in all of the specimens. This is due to the fact that multiple fine cracks, having a width lower than $0.1 \mathrm{~mm}$, formed in the jacket. Despite the growing number of cracks, the stress continuously increased up to peak, where the tensile strains localised in a single crack of the jacket and the failure occurred.

Table 5. The compressive strength and Young's modulus of UHP-FRCC used in the jackets.

\begin{tabular}{cccc}
\hline Series & Age & Compressive Strength (MPa) & Young' Modulus (GPa) \\
\hline \multirow{2}{*}{ FA0 } & 1 week & 193.8 & 46.34 \\
& 4 weeks & 197.93 & 45.90 \\
\hline \multirow{2}{*}{ FA20 } & 1 week & 193.31 & 43.39 \\
& 4 weeks & 179.65 & 43.38 \\
\hline \multirow{2}{*}{ FA50 } & 1 week & 146.97 & 36.20 \\
& 4 weeks & 154.55 & 37.66 \\
\hline \multirow{2}{*}{ FA70 } & 1 week & 121.50 & 33.40 \\
& 4 weeks & 121.98 & 34.12 \\
\hline
\end{tabular}


Table 6. The average values of the parameters measured in the uniaxial compression tests.

\begin{tabular}{|c|c|c|c|c|c|c|}
\hline Series & Jacket (mm) & $P_{\max }(k N)$ & $\sigma_{\max }(\mathrm{MPa})$ & $\sigma / f_{c_{-}}$CORE & $E_{\mathrm{cm}}(\mathrm{MPa})$ & $v$ \\
\hline \multirow{2}{*}{ FA0 } & 25 & 481.47 & 61.30 & 1.32 & 37.90 & 0.120 \\
\hline & 50 & 595.93 & 75.88 & 1.63 & 40.40 & 0.104 \\
\hline \multirow{4}{*}{ FA20 } & 25 & 463.86 & 59.06 & 1.27 & 37.48 & 0.179 \\
\hline & 37.5 & 499.80 & 63.64 & 1.37 & 38.30 & 0.157 \\
\hline & 50 & 515.27 & 65.61 & 1.41 & 38.67 & 0.125 \\
\hline & 75 & 663.53 & 84.48 & 1.82 & 41.70 & 0.121 \\
\hline \multirow{2}{*}{ FA50 } & 25 & 415.40 & 52.89 & 1.14 & 36.25 & 0.195 \\
\hline & 50 & 541.00 & 68.88 & 1.48 & 39.23 & 0.162 \\
\hline \multirow{3}{*}{ FA70 } & 25 & 396.07 & 50.43 & 1.08 & 35.74 & 0.216 \\
\hline & 37.5 & 418.40 & 53.27 & 1.15 & 36.66 & 0.168 \\
\hline & 50 & 516.60 & 65.78 & 1.41 & 38.70 & 0.123 \\
\hline \multicolumn{2}{|c|}{ Unconfined cylinders } & 356.37 & 46.52 & 1 & & \\
\hline
\end{tabular}

(a)

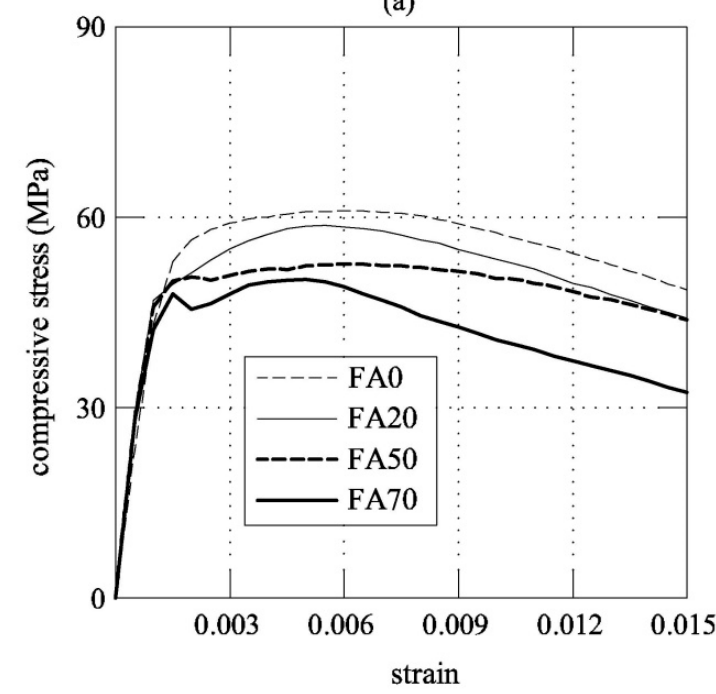

(b)

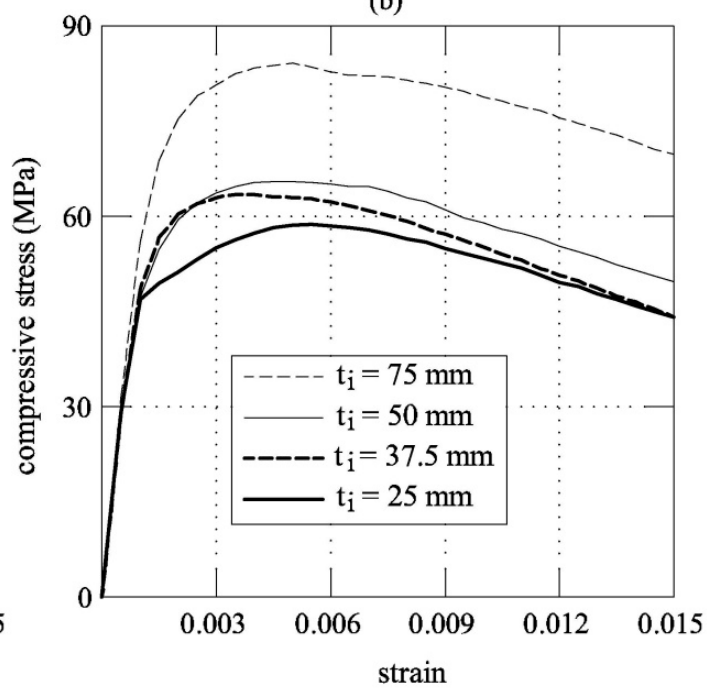

Figure 4. Stress-strain curves of the jacketed cylinders: (a) behaviour of different UHP-FRCC jackets having a constant of thickness $t_{\mathrm{i}}=25 \mathrm{~mm}$; (b) behaviour of the same UHP-FRCC jacket (FA20) having different thickness.

The composition of the UHP-FRCC binder considerably influences the mechanical performance of the column. In particular, the effect of the substitution strategy on the mechanical properties is evident in Figure $4 \mathrm{a}$, which reports the stress-strain curves of the concrete cylinders that were confined with a jacket of $25 \mathrm{~mm}$, but with $0 \%, 20 \%, 50 \%$, and $70 \%$ of cement being replaced by fly ash. The results that were obtained in the case of the FA20 mixture $\left(\sigma_{\max }=59.06 \mathrm{MPa}\right)$ are close to those that were achieved from the FA0 mixture $\left(\sigma_{\max }=61.30 \mathrm{MPa}\right)$. This is the same tendency of the results of UHP-FRCC material itself, as shown in Table 5. In other words, the replacement of $20 \%$ in weight of cement content is paid with a loss of $4 \%$ of the maximum compressive strength. When considering the cylinder confined with a jacked of FA 0 and $t_{\mathrm{i}}=25 \mathrm{~mm}$ as a reference, the decrement of the compressive strength is about $14 \%$ and $18 \%$ when $50 \%$ and $70 \%$ of cement is replaced by fly ash, respectively.

On the other hand, Figure $4 \mathrm{~b}$ reports the average stress-strain curves of the cylinders that were reinforced with the same type of jacket (FA20), but of different thickness (i.e., 25, 50, 37.5, and $70 \mathrm{~mm}$ ). In this case, the strength increases with the thickness of the reinforcing UHP-FRCC layer. 
For each UHP-FRCC series, Figure 5a shows the relationship between the thickness of the jacket and the strength of the reinforced cylinders. In all of the cases, the following linear relationship can be used to predict the compressive strength:

$$
\sigma_{\max }=s \cdot t_{i}+f_{\mathrm{c}_{-} \mathrm{CORE}}
$$

where $s=$ slope of the linear relationship. The coefficient $s$ can be separately computed for each series, as shown in Figure $5 b$, and the values can be plotted as a function of the replacement rate of cement with fly ash (see Figure 6). The slope gradually reduces as the percentage of substitution of cement increases $\left(C_{s u b}\right)$. Thus, the following linear correlation can be introduced:

$$
s=-0.004 \cdot C_{\text {sub }}+0.584
$$

where $s$ is measured in $\mathrm{MPa} / \mathrm{mm}$.
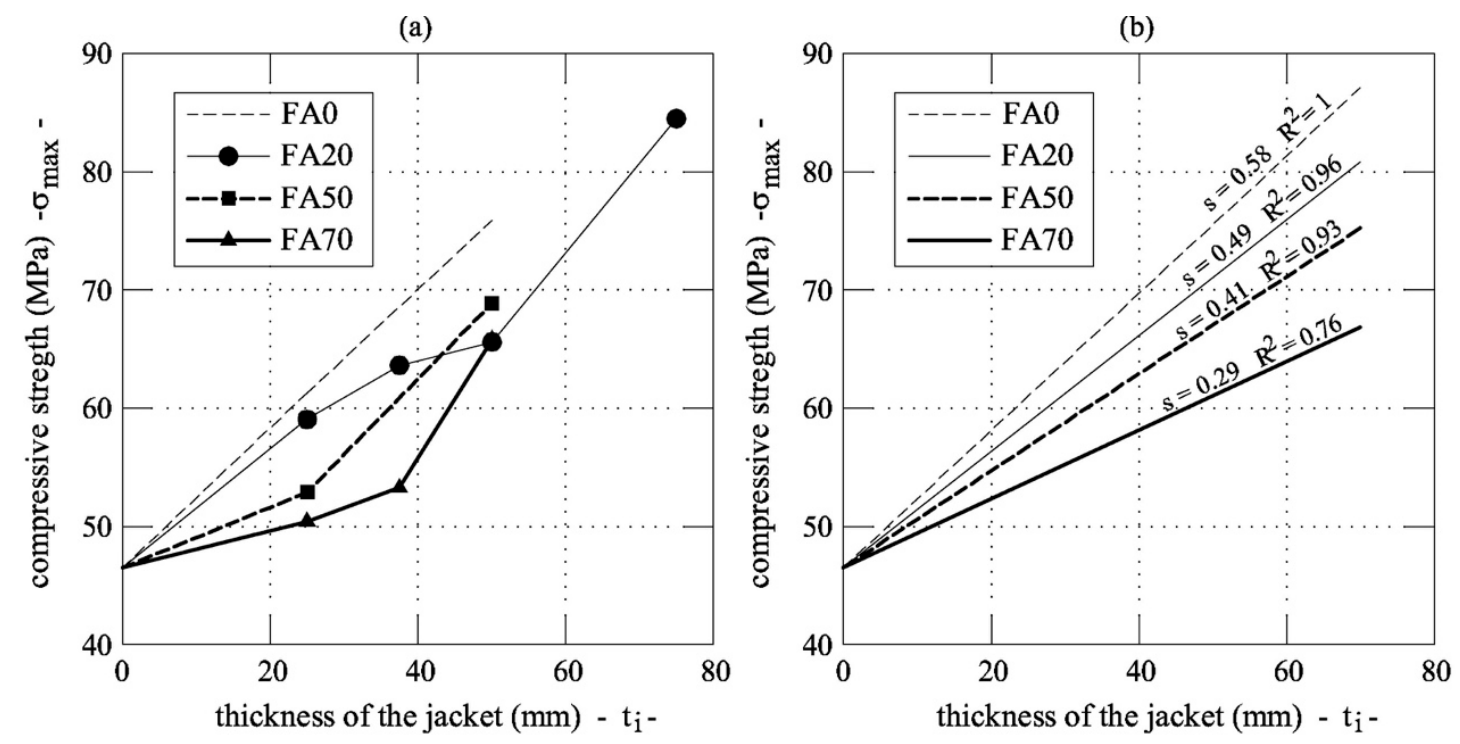

Figure 5. Compressive strength vs. thickness of jacket in the four ultra high performance fiber reinforced concrete (UHP-FRC) series investigated herein: (a) results from the tests; and, (b) the trend lines of the experimental data.

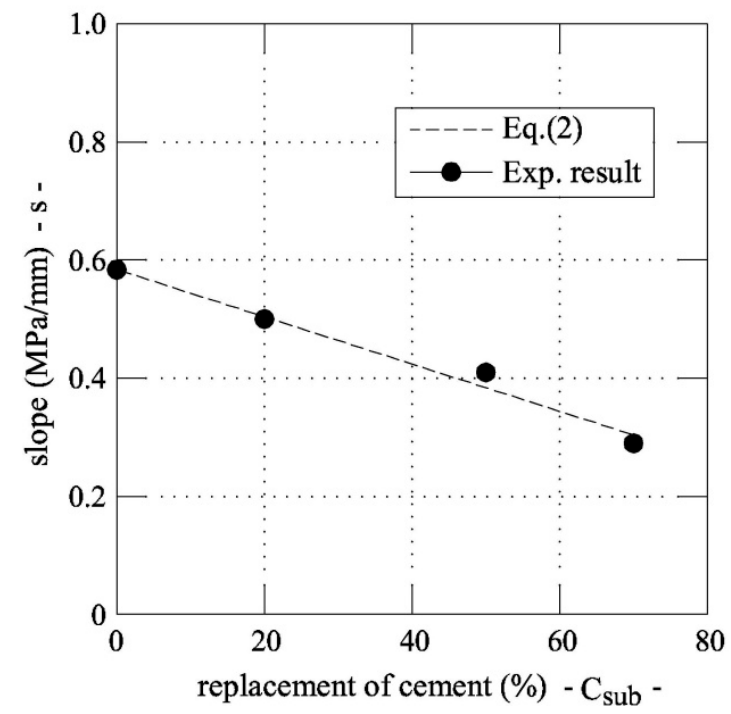

Figure 6. Formula for predicting the slope of the linear approximation of Equation (1). 


\subsection{Ecological Performances}

The parameter considered evaluating the ecological performances is the amount of $\mathrm{CO}_{2}$ related to the production of $1 \mathrm{~m}^{3}$ of UHP-FRCC. The amount of $\mathrm{CO}_{2}$ emitted per unit volume of each mixture is calculated in accordance with the inventory analysis [24] while using the values that were provided by the Japan Concrete Institute (JCI) [25], which listed the main materials used in cementitious composites and the relative carbon footprint. Such values are reported in Table 7 in terms of $\mathrm{kg}$ of $\mathrm{CO}_{2}$ released in the atmosphere for the production of one-ton of material.

Table 7. $\mathrm{CO}_{2}$ emissions of UHP-FRCC components [25].

\begin{tabular}{cc}
\hline Components & kg of $\mathbf{C O}_{\mathbf{2}} / \mathbf{t}$ \\
\hline LHC & 769 \\
FA & 29 \\
Sand & 4.9 \\
Water & 34.8 \\
SP & 150 \\
Fibers & 1320 \\
\hline
\end{tabular}

Figure 7 compares the environmental impacts of the various jackets, which were obtained by multiplying the values reported in Table 7 and the mass of materials used to cast the four series of UHP-FRCC. For the sake of completeness, Figure 7 also shows the values of some specimens that has not been tested. In this Figure, when the amount of cement replaced with fly ash is quite high $(>50 \%)$, the environmental impact is considerably reduced with respect to FA0 (it is halved for FA70). Moreover, it can be noticed that a reduced environmental impact is attained by decreasing the thickness of the jacket and, in parallel, by increasing the percentage of fly ash in the mixture. Here, the $\mathrm{CO}_{2}$ emission due to the steam curing is not taken into account, because all of the series were subjected to the same procedures and, subsequently, a comparative analysis among all of the specimens is performed.

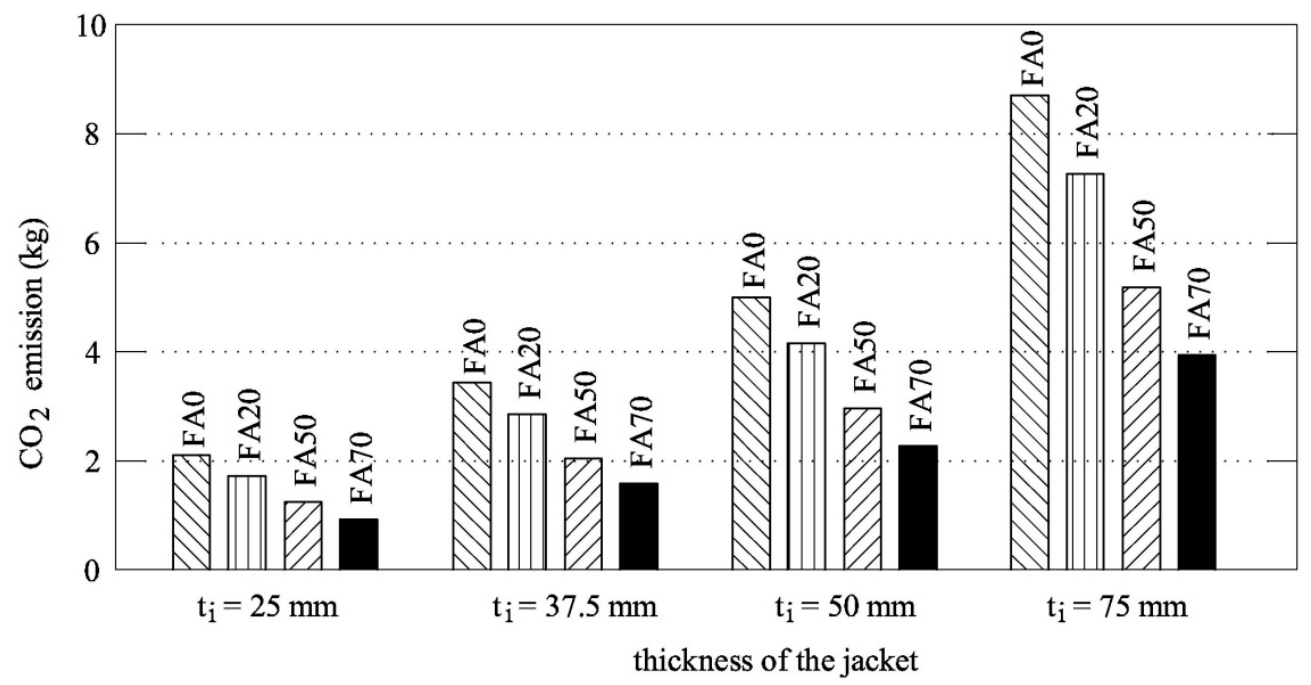

Figure 7. The ecological performances of the UHP-FRCC jackets used to reinforce concrete cores.

\subsection{Eco-Mechanical Analysis and Design Procedure}

By means of the approach that was proposed by Fantilli and Chiaia [19], ecological and mechanical analyses can be combined to define the best material. Compressive strength $\left(\sigma_{\max }\right)$ is considered as the functional unit, herein called the mechanical index (MI), whereas the ecological impact is evaluated through the carbon footprint (ecological index-EI). The reference values $\mathrm{MI}_{\text {inf }}$ (i.e., the minimum mechanical performance) and $\mathrm{EI}_{\text {sup }}$ (i.e., the maximum impact) are those of the concrete cylinder 
reinforced with the UHP-FRCC jacket without the substitution of cement with fly ash (i.e., FA0) and with a thickness $t_{\mathrm{i}}=25 \mathrm{~mm}$.

Figure 8 shows the non-dimensional chart that was used to perform the comparative analysis among the concrete specimens reinforced with the UHP-FRCC layer. In this diagram, the ratios $\mathrm{MI} / \mathrm{MI}_{\mathrm{inf}}$ and $\mathrm{EI}_{\text {sup }} / \mathrm{EI}$ are the abscissa and the ordinate, respectively. In other words, the following formula are used to define the non-dimensional axes in Figure 8:

$$
\begin{gathered}
\frac{\mathrm{MI}}{\mathrm{MI}_{\mathrm{inf}}}=\frac{\sigma_{\max }}{\sigma_{\max } \text { of FA0 with } t_{\mathrm{i}}=25 \mathrm{~mm}} \\
\frac{\mathrm{EI}_{\text {sup }}}{\mathrm{EI}}=\frac{\mathrm{kg} \mathrm{CO}_{2} \text { of FA0 with } t_{\mathrm{i}}=25 \mathrm{~mm}}{\mathrm{~kg} \mathrm{CO}_{2}}
\end{gathered}
$$

Most of the experimental results fall in Zone 2, where the mechanical performances are increased at the expense of an environmental impact higher than that of FA0 with $t_{\mathrm{i}}=25 \mathrm{~mm}$ (for which MI/MI $\mathrm{inf}_{\mathrm{inf}}$ $\left.=\mathrm{EI}_{\text {sup }} / \mathrm{EI}=1\right)$.

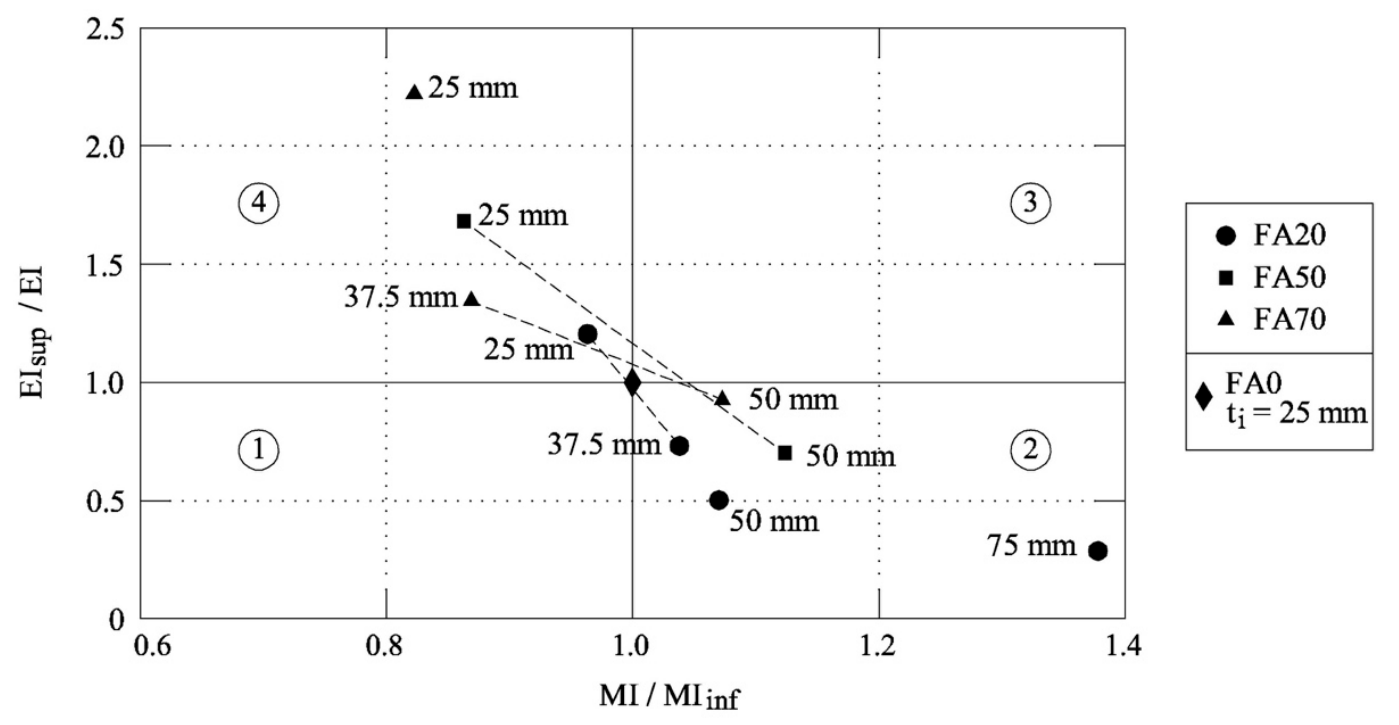

Figure 8. Eco-Mechanical analysis of the UHP-FRCC jackets [19].

However, a group of experimental values falls within Zone 4, which shows ecological performances greater than those shown by the reference specimen, but lower mechanical performances. Although none of the test results fall within Zone 3, where the ecological and mechanical performances are both improved, an area of the possible best solutions can be defined in Figure 8. More precisely, the UHP-FRCC jackets with a thickness between $37.5-50 \mathrm{~mm}$ and made with FA70 series, and those of the FA50 series with thickness being included in the range $25-50 \mathrm{~mm}$ (see the dashed lines), might perform better than the reference cylinders (i.e., part of the dashed lines falls within Zone 3). The same is also valid for some thickness (within the range $25 \sim 37.5 \mathrm{~mm}$ ) of the series FA20, as evidenced by the dashed line that is reported in Figure 8.

Nevertheless, Equations (1) and (2) can be used to relate the compressive stress, the thickness of the jacket, and the type of fiber-reinforced concrete to design the exact UHP-FRCC layer. In particular, the design procedure that is shown in Figure 9 can be introduced with the aim of increasing the strength of the UHP-FRCC jacketing system, and reducing the $\mathrm{CO}_{2}$ emissions as well. 


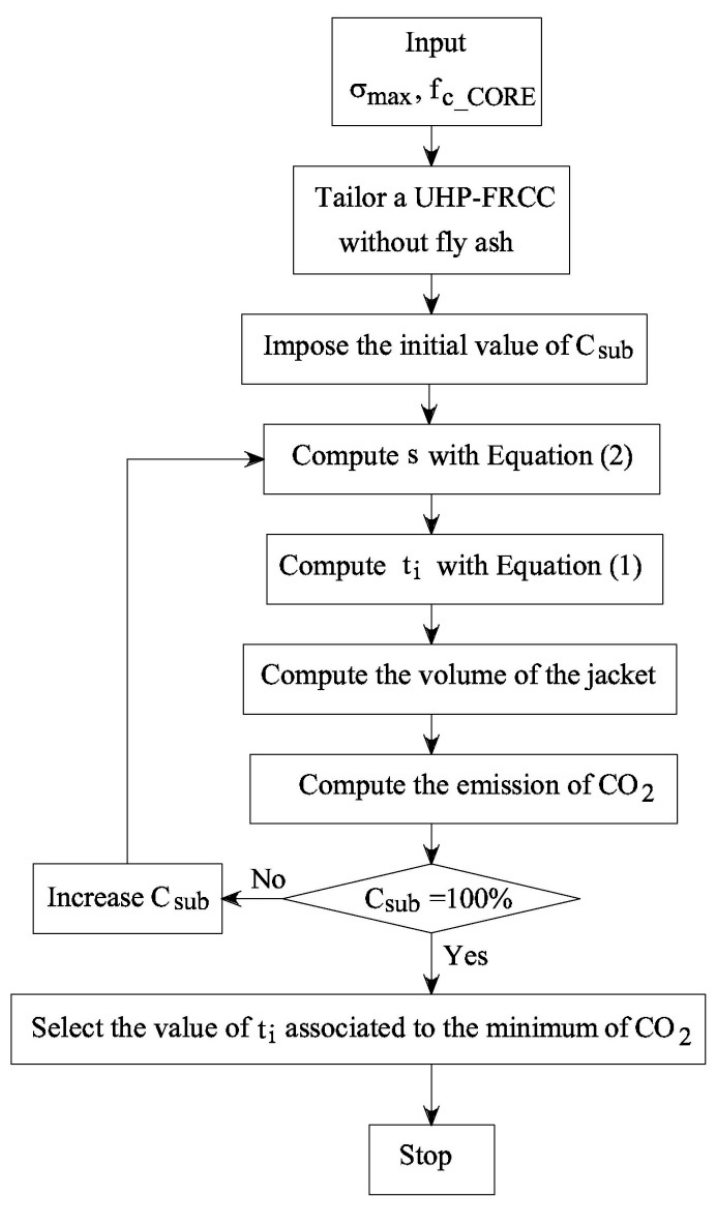

Figure 9. The design procedure used to optimize the UHP-FRCC jacket of the concrete columns.

As a result, Figure 10 shows the curves that relate the $\mathrm{CO}_{2}$ emissions with the percentage of cement replaced by fly ash for three values of the compressive strength $\sigma_{\max }$ (i.e., 55, 65, and $75 \mathrm{MPa}$ ). For each load carrying capacity, four thicknesses of the jackets have been obtained referring to the mixtures FA0, FA20, FA50, and FA70.

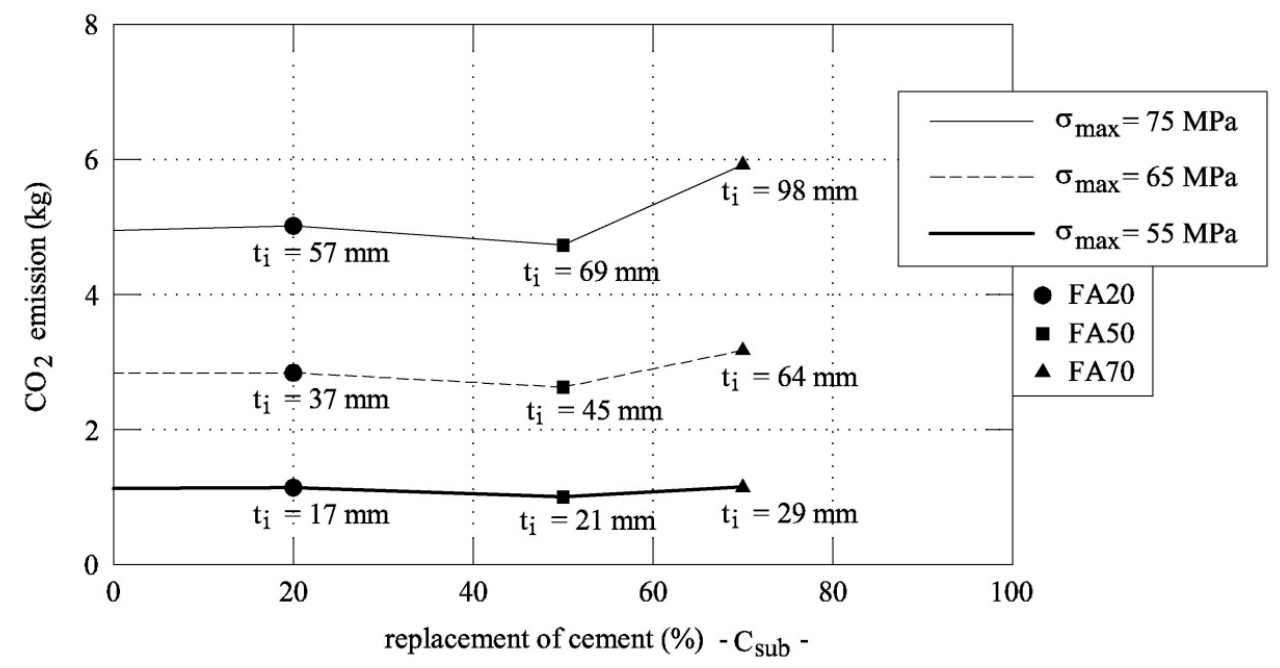

Figure 10. The ecological impact of UHP-FRCC jackets made with different mixtures (having different $\left.\sigma_{\max }\right)$. 
If $\sigma_{\max } \leq 55 \mathrm{MPa}$ is required, the $\mathrm{CO}_{2}$ emission does not change with the thickness or the percentage of cement replacement with fly ash. Conversely, as the required strength increases, the corresponding $\mathrm{CO}_{2}$ emission has a minimum in correspondence of a specific thickness. For instance, the optimal replacement of cement with fly ash to achieve a compressive stress of $75 \mathrm{MPa}$ is $50 \%$ and the corresponding thickness is $67 \mathrm{~mm}$. In the three curves that are shown in Figure 10, the best substation rate is at 50\%, as obtained by Fantilli et al. [26] in the reinforced concrete beam. Indeed, for lower substitution rates, thickness reduces, but the $\mathrm{CO}_{2}$ emissions are higher.

When the substitution strategy is forced to higher percentages, the same mechanical performances can only be obtained through solutions with a high environmental impact, as the thickness of the jacket increases. In other words, the UHP-FRCC jacket with a low fly ash content shows mechanical performances that are not compensated by the environmental impact. In the same way, the jacketing system is so thick to produce a large environmental impact for large substitutions of cement.

\section{Conclusions}

According to the results of the tests previously described, the following conclusions are drawn:

- A linear relationship between the thickness of the jacket and the compressive strength of concrete columns has been found. By means of this relationship, the thickness of the UHP-FRCC jacket might be adjusted to achieve the desired mechanical performances.

- The strength of the confined column linearly decreases as the substitution of cement with fly ash increased in the UHP-FRCC jacket.

- Through the eco-mechanical analysis, it is possible to demonstrate that the partial replacement of cement with fly ash, combined with a suitable thickness of the jacket, might simultaneously guarantee the best mechanical and ecological performances.

- A design procedure has been introduced to optimise the UHP-FRCC jacketing system and reduce the environmental impact as well. Particularly, for a given strength of the column, the impact of the UHP-FRCC jacket has a minimum in correspondence of a substitution rate of cement with fly ash that is close to $50 \%$.

Author Contributions: Conceptualization, T.N. and A.P.F.; Methodology, T.N., G.I. and A.P.F.; Validation, T.N. and A.P.F.; Investigation, L.P.M., T.N. and A.P.F.; Resources, L.P.M. and T.N.; Writing-Original Draft Preparation, L.P.M. and A.P.F.; Writing-Review \& Editing, T.N. and A.P.F.; Visualization, L.P.M. and A.P.F.; Project Administration, T.N. and A.P.F.

Funding: This work was partially supported by JSPS KAKENHI Grant Number 17H03337. The authors would like to express their deep gratitude.

Conflicts of Interest: The authors declare no conflict of interest.

\section{References}

1. Richard, P.; Cheyrezy, M. Composition of reactive powder concretes. Cem. Concr. Res. 1995, 25, $1501-1511$. [CrossRef]

2. Yu, R.; Spiesz, P.; Brouwers, H.J.H. Mix design and properties assessment of Ultra-High Performance Fibre Reinforced Concrete (UHPFRC). Cem. Concr. Res. 2014, 56, 29-39. [CrossRef]

3. Kwon, S.; Nishiwaki, T.; Kikuta, T.; Mihashi, H. Development of ultra-high-performance hybrid fiber-reinforced cement-based composites. ACI Mater. J. 2014, 111, 309-318. [CrossRef]

4. Resplendino, J. Introduction: What is UHPFRC? In Designing and Building with Ultra-High Performance Fibre-Reinforced Concrete (UHPFRC): State of the Art and Development; Toutlemonde, F., Resplendino, J., Eds.; John Wiley \& Sons, Inc.: London, UK, 2011; pp. 3-12.

5. Park, S.H.; Kim, D.J.; Ryu, G.S.; Koh, K.T. Tensile behaviour of Ultra-High Performance Hybrid Fibre Reinforced Concrete. Cem. Concr. Compos. 2012, 34, 172-184. [CrossRef]

6. Rossi, P. Influence of fibre geometry and matrix maturity on the mechanical performance of ultra-high-performance cement-based composites. Cem. Concr. Compos. 2013, 37, 246-248. [CrossRef] 
7. Wille, K.; El-Tawil, S.; Naaman, A.E. Properties of strain hardening ultra high performance fiber reinforced concrete (UHP-FRC) under direct tensile loading. Cem. Concr. Compos. 2014, 48, 53-66. [CrossRef]

8. Brühwiler, E. "Structural UHPFRC": Welcome to the post-concrete era! In Proceedings of the First International Interactive Symposium on UHPC, Des Moines, IA, USA, 18-20 July 2016.

9. Kosaka, Y.; Imai, T.; Kunieda, M.; Mitamura, H.; Matsui, S. Development of High Performance Fibre Reinforced Concrete for Rehabilitation of Bridge Deck Slab. In Proceedings of the International Conference on the Regeneration and Conservation of Concrete Structures RCCS, Nagasaki, Japan, 1-3 June 2015.

10. Noshiravani, T.; Brühwiler, E. Rotation capacity and stress redistribution ability of R-UHPFRC-RC composite continuous beams: An experimental investigation. Mater. Struct. 2013, 46, 2013-2028. [CrossRef]

11. Habert, G.; Roussel, N. Study of two concrete mix-design strategies to reach carbon mitigation objectives. Cem. Concr. Compos. 2009, 31, 397-402. [CrossRef]

12. Turner, L.; Collins, F. Carbon dioxide equivalent (CO2-e) emissions: A comparison between geopolymer and OPC cement concrete. Constr. Build. Mater. 2013, 43, 125-130. [CrossRef]

13. Mehta, P.K.; Monteiro, P.J.M. Concrete-Microstructure, Properties and Materials; McGraw-Hill: New York, NY, USA, 2014.

14. Nishiwaki, T.; Suzuki, K.; Kwon, S.; Igarashi, G.; Fantilli, A.P. Ecological and Mechanical Properties of Ultra High Performance-Fiber Reinforced Cementitious Composites containing High Volume Fly Ash. In Proceedings of the 4th International RILEM Conference on Strain-Hardening Cement-Based Composites (SHCC4), Dresda, Germany, 18-20 September 2017.

15. Shaikh, F.U.; Nishiwaki, T.; Kwon, S. Effect of fly ash on tensile properties of ultra-high performance fiber reinforced cementitious composites (UHP-FRCC). J. Sustain. Cem. Based Mater. 2018, 7, 1-15. [CrossRef]

16. Yu, R.; Spiesz, P.; Brouwers, H.J.H. Development of an eco-friendly Ultra-High Performance Concrete (UHPC) with efficient cement and mineral admixtures uses. Cem. Concr. Compos. 2015, 55, 383-394. [CrossRef]

17. Yalçınkaya, Ç.; Yazıcı, H. Effects of ambient temperature and relative humidity on early-age shrinkage of UHPC with high-volume mineral admixtures. Constr. Build. Mater. 2017, 144, 252-259. [CrossRef]

18. Aghdasi, P.; Ostertag, C.P. Green ultra-high performance fiber-reinforced concrete (G-UHP-FRC). Constr. Build. Mater. 2018, 190, 246-254. [CrossRef]

19. Fantilli, A.; Chiaia, B. The work of fracture in the eco-mechanical performances of structural concrete. J. Adv. Concr. Technol. 2013, 11, 282-290. [CrossRef]

20. Japan Industrial Standards. JIS R 5201:2015 Physical Testing Methods for Cement; Japanese Standards Association: Tokyo, Japan, 2015.

21. ASTM International. ASTM C1437-15 Standard Test Method for Flow of Hydraulic Cement Mortar; ASTM International: West Conshohocken, PA, USA, 2015.

22. Japan Industrial Standards. JIS A 1149:2010 Method of Test for Static Modulus of Elasticity of Concrete; Japanese Standards Association: Tokyo, Japan, 2010.

23. International Organization for Standardization. ISO 6784:1982 Concrete-Determination of Static Modulus of Elasticity in Compression; American National Standards Institute (ANSI): New York, NY, USA, 1982.

24. Itsubo, N.; Sakagami, M.; Washida, T.; Kokubu, K.; Inaba, A. Weighting across safeguard subjects for LCIA through the application of conjoint analysis. Int.J. Life Cycle Assess. 2004, 9, 196-205. [CrossRef]

25. Japan Concrete Institute. Textbook for Environmental Aspects of Concrete (Tentative); Concrete Institute: Tokyo, Japan, 2013. (In Japanese)

26. Fantilli, A.P.; Tondolo, F.; Chiaia, B.; Habert, G. Designing Reinforced Concrete Beams Containing Supplementary Cementitious Materials. Materials 2019, 12, 1248. [CrossRef] [PubMed]

(C) 2019 by the authors. Licensee MDPI, Basel, Switzerland. This article is an open access article distributed under the terms and conditions of the Creative Commons Attribution (CC BY) license (http://creativecommons.org/licenses/by/4.0/). 